\title{
Molecular epidemiology of poliovirus infection in Tunisia
}

\author{
H. TRIKI, O. BAHRI, S. GUILLOT*, H. G. A. M. VAN DER AVOORT†, J. BEN SASSI, A. ARROUJI, \\ Z. ARROUJI $\ddagger$, A. SLIM $\ddagger$ R. CRAINIC* and K. DELLAGI
}

WHO Regional Reference Laboratory on Poliomyelitis, Institut Pasteur, Tunis, Tunisia, * Unité de Virologie Médicale, Institut Pasteur, Paris, France, †Laboratory of Virology, National Institute of Public Health and Environmental Protection (RIVM), Bilthoven. The Netherlands and $\ddagger$ Laboratoire de Microbiologie, Hôpital Charles Nicolle, Tunis, Tunisia

This report is an overview of poliomyelitis surveillance in Tunisia from 1991 to 1996. In all, 2088 stool specimens, collected from 152 acute flaccid paralysis (AFP) cases and from 1747 of their healthy contacts were investigated. Virus isolation was done systematically in RD and HEp-2C cell lines and isolated viruses were typed by seroneutralisation as polioviruses or non-polio enteroviruses. Poliovirus isolates were analysed systematically for their wild or vaccine-related origin by two methods - one based on antigenic differences and one on genetic differences between strains. All type 2 polioviruses were vaccine-related and most wild viruses belonged to polio serotype 3 . Wild polio type 3 viruses were detected in 1991 and 1992 in six cases of paralytic polio. A silent circulation of wild polio 1 and wild polio 3 was detected in 1994. No wild virus was detected in Tunisia from 1995 onwards. Wild polioviruses were sequenced and compared with Tunisian wild strains isolated during the 1980s, as well as other genotypes from the international database. These investigations revealed a single Tunisian polio 3 genotype that has been circulating from 1985 to 1994 and two different polio 1 genotypes. These results reflect effective control strategies within the country and contribute to the improvement of the polio eradication programme effectiveness at national and global levels.

\section{Introduction}

Paralytic poliomyelitis is the second viral disease after smallpox which has been proposed as the target for worldwide eradication [1]. An eradication programme was started in 1988 and today, poliomyelitis is very rare in all developed and many developing countries [2]. The key operational components of this programme are mass vaccination of the population and effective virological surveillance of wild virus circulation. This surveillance is based on a complete virological investigation of all acute flaccid paralysis (AFP) cases, including virus isolation from stool specimens collected from patients and from their contacts and serotyping of isolated viruses, followed by intratypic differentiation of all polioviruses as wild or vaccine-derived. The certification of poliomyelitis eradication in a region requires that no wild poliovirus is isolated despite an effective AFP surveillance

Received 20 Jan. 1998; revised version accepted 1 Oct. 1998 Corresponding author: Dr H. Triki. system. Because of the extensive use of attenuated oral polio vaccine (OPV) which results in frequent isolation of vaccine viruses from children, intratypic differentiation of isolated polioviruses constitutes an essential step in the diagnostic process. Various methods have been developed; some are based on the antigenic phenotype with a panel of monoclonal antibodies or intratype-specific cross-absorbed antisera [3-7]. Others are genomic methods based on probe hybridisation or PCR amplification [8-18]. Molecular characterisation of isolated strains by sequencing of highly variable genomic regions gives more detailed information about the geographic origin and the relationship between strains [19-25].

In Tunisia, triple dose OPV coverage in infants $<12$ months of age has been $>90 \%$ since 1988 . Paralytic poliomyelitis has become rare, with an average of only one case per year since 1988 (two cases in 1988, no cases in 1989 and 1990, three cases in 1991, four cases in 1992 and no cases from 1993 to 1996). Virological surveillance of AFP cases was started in 1991. Subsequently, six paralytic polio cases 
due to wild poliovirus type 3 occurred within a period of 5 months from December 1991 to April 1992 [26]. It was suggested that this higher incidence of the disease was the result of an improved surveillance system [27]. These were the last wild polio paralytic cases notified in the country. More detailed information about the epidemiological situation of poliomyelitis and the national programme for AFP surveillance in Tunisia has been published [28].

In this report, an overview of the virological surveillance of poliomyelitis in Tunisia from 1991 to 1996 is given. The results of the molecular analysis of poliovirus strains isolated during this period are presented.

\section{Materials and methods}

\section{Subjects}

A total of 2088 stool specimens was investigated, collected between Dec. 1991 and Dec. 1996; 341 specimens were from 152 AFP cases (infants aged 4 months-16 years, average 4 years). Contacts of 137 cases were sampled. The total number of stool samples collected was 1747 (average of 13 contacts per AFP index case; range 2-187).

\section{Virus isolation and identification}

All stool specimens were processed for virus isolation and identification by standard protocols recommended by WHO [29]. Briefly, after a decontamination step with chloroform and antibiotics, stools were inoculated onto RD and HEp2-Cincinatti cell lines. Specimens were considered negative if no cytopathic effect (CPE) was detected 14 days after inoculation. For positive samples, isolated viruses were tested for sero-neutralisation of CPE with trivalent and bivalent pools of antisera against polio 1 , polio 2 and polio 3 and pools against Coxsackie B and echoviruses (RIVM, the Netherlands).

\section{Intratypic differentiation of polioviruses}

All polioviruses were tested systematically by two distinct methods to establish their wild or vaccine origin [30]: one method was based on antigenic differences and the second was based on genetic differences between strains. The antigenic method was an ELISA with cross-absorbed intratype-specific rabbit antisera $[3,5,6]$. The genetic method was a hybridisation assay with recombinant riboprobes which specifically hybridise to the genome of vaccine-related isolates $[13,18]$. The combination of these two methods was recently shown to be the most appropriate and recommended for use in the WHO polio laboratory network [30]. Polioviruses found to be unrelated to the OPV strains by one of the two methods were then analysed by partial genome sequencing.

\section{Sequence analysis}

Genetic characterisation of wild strains was performed by partial sequencing of a PCR product including the 150-bp fragment used for molecular epidemiological analysis and located in the VP1/2A junction region between nucleotides 3287 and 3436 for polio 3, and 3296 and 3445 for polio 1 [31].

Virus preparation. Wild viruses were re-inoculated on HEp2C cell cultures which were freeze-thawed when full cytopathic effect was obtained. The cell culture suspensions were subsequently clarified by centrifugation $(20 \mathrm{~min}$ at $1500 \mathrm{~g}$ ) and used directly for cDNA synthesis.

Reverse transcription and PCR. $20 \mathrm{U}$ of RNAasin ( $1 \mu 1)$ and $50 \mathrm{pM}(1 \mu \mathrm{l})$ of downstream primer UC11 (nt 3485-3504) were added to $12 \mu 1$ of virus suspension. The mixture was heated for $5 \mathrm{~min}$ at $80^{\circ} \mathrm{C}, 5 \mathrm{~min}$ at $42^{\circ} \mathrm{C}$ and then immediately chilled on ice. Six $\mu \mathrm{l}$ of a reverse transcription mixture were then added containing $10 \mathrm{~mm}$ each of four deoxynucleotides, $1 \mathrm{U}$ Avian Myeloblastosis Virus Reverse Transcriptase (Gibco BRL), $6 \mathrm{mM} \quad \mathrm{MgCl}_{2}, 50 \mathrm{mM}$ Tris- $\mathrm{HCl}$ (pH 8.3), $10 \mathrm{mM}$ DTT, $40 \mathrm{mM} \mathrm{KCl}$. The mixture was incubated for $30 \mathrm{~min}$ at $42^{\circ} \mathrm{C}$, heat-denatured for $5 \mathrm{~min}$ at $95^{\circ} \mathrm{C}$ and immediately stored on ice for a minimum of $5 \mathrm{~min}$. The whole volume of the cDNA was subsequently used for PCR: $80 \mu \mathrm{l}$ of a mixture were added, containing $50 \mathrm{pM}$ of upstream primer UG1 (nt 2402-2421), 1.25 U Taq polymerase (Amersham), $50 \mathrm{mM} \mathrm{KCl}, 1.5 \mathrm{mM} \mathrm{MgCl}_{2}, 10 \mathrm{mM}$ Tris- $\mathrm{HCl}$ (pH 8.3). Light mineral oil (Sigma) $100 \mu \mathrm{l}$ was layered on to the samples, which were then subjected to 30 cycles of $10 \mathrm{~s}$ denaturation at $94^{\circ} \mathrm{C}, 1 \mathrm{~min}$ annealing at $45^{\circ} \mathrm{C}$ and $1 \mathrm{~min}$ extension at $70^{\circ} \mathrm{C}$ in a programmable thermal cycler (Perkin Elmer Cetus). A final extension of $10 \mathrm{~min}$ at $70^{\circ} \mathrm{C}$ completed the procedure. Finally, $5 \mu \mathrm{l}$ of the RT-PCR product were loaded on to a agarose $1.5 \%$ gel (Sigma) to which ethidium bromide was added to estimate the size and amount of amplified DNA. For strains which could not be amplified, RTPCR was conducted again in the same conditions, but with different dowmstream primer, UC13 (3629-3648) or another upstream primer UG19 (2870-2891), or both.

Purification of the RT-PCR products. The remaining PCR products were electrophoresed again in a low melting gel $0.8 \%$ containing ethidium bromide and the band of interest was cut out of the gel and purified by phenol extraction and ethanol precipitation. The DNA was resuspended in $20 \mu \mathrm{l}$ of sterile distilled water.

Sequencing of PCR products. Purified PCR products were sequenced by the dideoxy method with the Sequenase kit (United States Biochemical), following the manufacturers recommendations. Samples were electrophoresed through a polyacrylamide $7 \%$ gel 
which was then fixed for 15-39 min dried and exposed to X-ray film for 2 days.

Data analysis. Sequence relationship among poliovirus genomes (dendrograms) was analysed with the UPGMA program (Gene Work DNA and Protein Analysis Package, 2, 3; intelliGenetics). Sequences of Tunisian strains were compared with each other and with other strains isolated in the Mediterranean and African regions.

\section{Results}

\section{AFP detection and investigation rates}

The number of AFP cases detected and those virologically investigated by year are shown in Table 1 . The population under 15 years in Tunisia is estimated at c. 3 million. Accordingly, the AFP detection rate per 100000 children aged $<15$ years increased from 0.2 in 1991 to 1.5 and $1.3 \%$ in 1995 and 1996 respectively. The investigation rate (cases investigated/cases detected) was $>80 \%$ after 1992 .

\section{Virus isolation, serotyping and intratypic differentiation}

Of the 2088 stool specimens tested, 1848 were negative; polioviruses were isolated in 101 specimens and non-polio enteroviruses (NPEV) in 139 specimens. The number of polio positives, by year, in paralytic cases and in contacts, is given in Table 1. Intratypic differentiation was performed by ELISA and probe hybridisation for all poliovirus isolates : 29 polio 1,12 polio 2 and 45 polio 3 (five stools contained a mixture of more than one polio serotype). The results were concordant between the two methods for all strains. Serotypes and intratypic differentiation, according to the year of isolation, in paralytic cases or in the healthy population, are shown in Fig. 1. All type 2 polioviruses were found to be vaccine-related. All type 1 polioviruses were also vaccine-related, except for one strain isolated in 1994 from a healthy contact of an AFP case. No type 3 polioviruses isolated in 1991 and 1992 were related to OPV strains. Viruses from two contacts of an AFP case detected in 1994 were also not of vaccine-

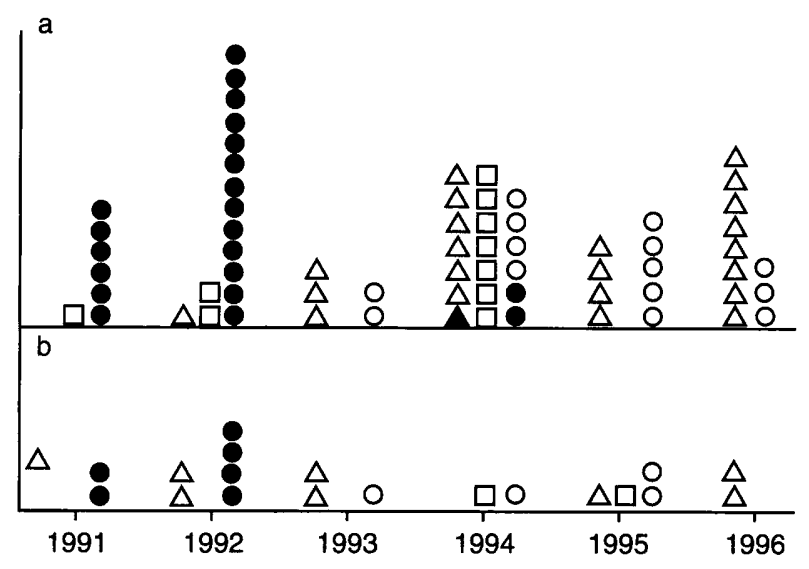

Fig. 1. Serotypes and intratypic differentiation of polioviruses isolated from (a) healthy children and (b) cases of paralytic poliomyelitis: $\Delta$, vaccine-related type $1 ; \boldsymbol{\Lambda}$, wild-type $1 ; \square$, vaccine-related type $2 ; \mathbf{\square}$, wild-type 2 ; $\bigcirc$, vaccine-related type $3 ; \mathbf{O}$, wild-type 3 .

type. All type 3 polioviruses isolated in 1993, 1995 and 1996 were vaccine-related.

\section{Geographic distribution, clinical features and case classification}

The six paralytic cases caused by wild polio 3 in 1991 and 1992 occurred in five distinct geographical areas. With the exception of the second case in 1991, which occurred in a contact of the first case, no epidemiological link could be found between the other cases. Some polio 3 wild-type strains isolated in 1993 and 1988 were from the same district. The classification of AFP cases as polio or non-polio was done by a national committee comprising neurologists, epidemiologists, paediatricians, infectious disease specilaists and representatives from the National Poliomyelitis Reference Laboratory and the National Immunization Programme. The case classification was based on the results of virological investigation, the clinical features of the disease and electromyography, the clinical evolution of the symptoms and the results of a systematic follow-up visit 60 days after onset of paralysis. Among the six AFP cases reported in 1991, three were classified as poliomyelitis cases, wild polio 3 was identified in two cases and one patient was lost to follow-up before stool

Table 1. Studied population and poliovirus isolation

\begin{tabular}{|c|c|c|c|c|c|c|}
\hline \multirow[b]{2}{*}{ Year } & \multicolumn{2}{|c|}{ AFP cases } & \multicolumn{2}{|c|}{ Stools collected from patients } & \multicolumn{2}{|c|}{ Stools collected from contacts } \\
\hline & $\begin{array}{c}\text { Detected } \\
\text { (Detection rate*) }\end{array}$ & $\begin{array}{c}\text { Investigated } \\
\left(\text { Investigation } \text { rate }^{\dagger}\right)\end{array}$ & Total & $\begin{array}{l}\text { Polio positive } \\
\text { cases (stools) }\end{array}$ & Total & Polio positive \\
\hline 1991 & $6(0.2)$ & $2 \quad(33 \%)$ & 10 & $2(10)$ & 30 & 6 \\
\hline 1992 & $18(0.6)$ & $18(100 \%)$ & 42 & $5(9)$ & 679 & 15 \\
\hline 1993 & $29(0.9)$ & $28 \quad(96 \%)$ & 64 & $3(7)$ & 226 & 5 \\
\hline 1994 & $28(0.9)$ & $26 \quad(92 \%)$ & 52 & $2(3)$ & 208 & 17 \\
\hline 1995 & $45(1.5)$ & $39(86 \%)$ & 91 & $4(7)$ & 363 & 9 \\
\hline 1996 & $41(1.3)$ & $39(95 \%)$ & 82 & 2 (3) & 241 & 10 \\
\hline Total & $167(-)$ & $(91 \%)$ & 341 & $18(39)$ & 1747 & 62 \\
\hline
\end{tabular}

*Per 100000 children aged $<15$ years.

$\dagger$ Investigated/detected. 
specimens could be obtained. In 1992, among the 18 AFP cases reported, four were confirmed as poliomyelitis due to wild-type 3 poliovirus. In 1993, no wild virus was detected and vaccine-derived polioviruses were detected in three paralytic cases among which only one was classified as vaccine-associated paralytic poliomyelitis.

In 1994, all AFP cases detected were classified as non-polio-related. The AFP case in which wild polioviruses type 1 and type 3 were identified in the contacts was not considered by the committee as a poliomyelitis case according to the following criteria. (i) The virological investigation of the case itself proved negative - two stool specimens collected within 14 days of onset of paralysis and received by the laboratory within $24 \mathrm{~h}$ in an adequate condition were found to be negative. (ii) Clinical and electromyographic features were highly compatible with a Guillain-Barré syndrome - symmetrical paralysis of the two legs, albumin-cytologic dissociation in the cerebro-spinal fluid, slowed conduction and decreased motor amplitudes by electromyography. (iii) There was complete clinical and electromyographical recovery with no persistent sequelae. The isolation of wild polioviruses in the contacts of this case were considered to represent detection of silent circulation of wild poliovirus. All AFP cases detected in 1995 and 1996 were classified as non-polio-related.

\section{Relationships among wild polioviruses}

Genomic sequencing was performed on eight selected wild strains: the wild polio 1 isolated in 1994 (PV1/MED125/TUN94), one of the two wild polio 3 viruses isolated in 1991 (PV3/KEBILI3/TUN91), the viruses isolated from four polio cases in 1992 and another strain isolated from a healthy child in a different district (PV3/TOZEUR18/TUN92, PV3/ KEF54/TUN92, PV3/GAFSA12/TUN92, PV3/ NEFTA55/TUN92, PV3/SIDIBOUZ62/TUN92) and one of the two wild polio 3 strains isolated in 1994 (PV3/MED126/TUN94). Two supplemental serotype 1 wild strains, isolated in Tunisia in 1986 and in Algeria in 1990, as well as one Tunisian serotype 3 wild strain isolated in 1988 were also sequenced. The nucleotide sequence relationships among Tunisian strains and their relationship with other polioviruses that have circulated in Mediterranean and African countries are represented in dendrograms (Fig. 2, polio 3; Fig. 3, polio 1 sequences). All Tunisian polio 3 sequences grouped into a single cluster representing a separate genotype. The most closely related strain available in the Netherlands laboratory database was also from Tunisia and was isolated in 1985. The oldest strains from 1985 and 1988 were more related to each other than the two later strains from 1991 to 1994 . These results illustrate continuous circulation of a Tunisian genotype 3 poliovirus between 1985 and 1994. With regard to the polio 1 viruses, the strain from Algeria and the Tunisian strain from 1986 were related to each other ( $6 \%$ difference in the nucleotide sequences), but no other related sequence was identified in the database. The Tunisian isolate from 1994 was completely different from the other two isolates and is in fact also distinct from known genotypes - there is $>18 \%$ difference from the most related sequences within the database. It is difficult to postulate an origin for this isolate.

\section{Discussion}

In 1988, the World Health Assembly (WHA) committed WHO to the global eradication of poliomyelitis by the year 2000 [1]. Surveillance of cases of poliomyelitis and of the circulation of wild-type poliovirus in man plays a crucial role in attaining this goal. AFP surveillance, although non-specific for the detection of poliovirus infections, has been found to be the most sensitive strategy. AFP encompasses a range of disorders including Guillain-Barré syndrome and paralysis associated with non-polio enteroviruses; thus, virological analysis of clinical specimens must be undertaken to investigate the possible aetiological role of wild polioviruses. Nucleotide sequence analysis of the VP1/2A junction region of the poliovirus genome has proved to be an excellent tool for genotyping poliovirus strains from different geographic regions [19-22, 24], although the analysed sequence is only 150 nucleotides long. A genotype is generally defined as a group of polioviruses having $<15 \%$ nucleotide differences within the VP1/2A region [19]. Sequence comparisons of poliovirus isolates have revealed the existence of numerous genotypes endemic to different regions of the world $[19,21,22,25,31]$. The high frequency of international travel increases the risk of inter-country transmission of poliovirus worldwide. Importation of polioviruses from endemic countries to basically poliofree areas has been reported $[22,31-37]$.

Fig. 2. Sequence relatedness among polio 3 strains. Dendrogram summarising sequence relatedness among polio 3 strains across the nucleotides $3287-3436$ in the VP1/2A region [20]. The strains are designated by their serotype, laboratory number, country and year of isolation respectively. The name of the district of isolation is given between the serotype and the laboratory number for strains analysed in this study. The other strains belong to the international database (RIVM-Bilthoven, the Netherlands). Country abbreviations for Figs. 2 and 3 are: ALG, Algeria; COL, Colombia; CYP, Cyprus; EGY, Egypt; ETH, Ethiopia; FIN, Finland; IND, India; IRQ, Iraq; ISR, Israel; JOR, Jordan; KEN, Kenya; NET, Netherlands; SOM, Somalia; SRL, Sri Lanka; SUD, Sudan; SYR, Syria; TUN, Tunisia; TUR, Turkey; USA, United States of America. Percentage nucleotide sequence divergence is indicated above the dendrogram branches. The two Tunisian strains in the low part of the dendrogram are vaccine-related. 


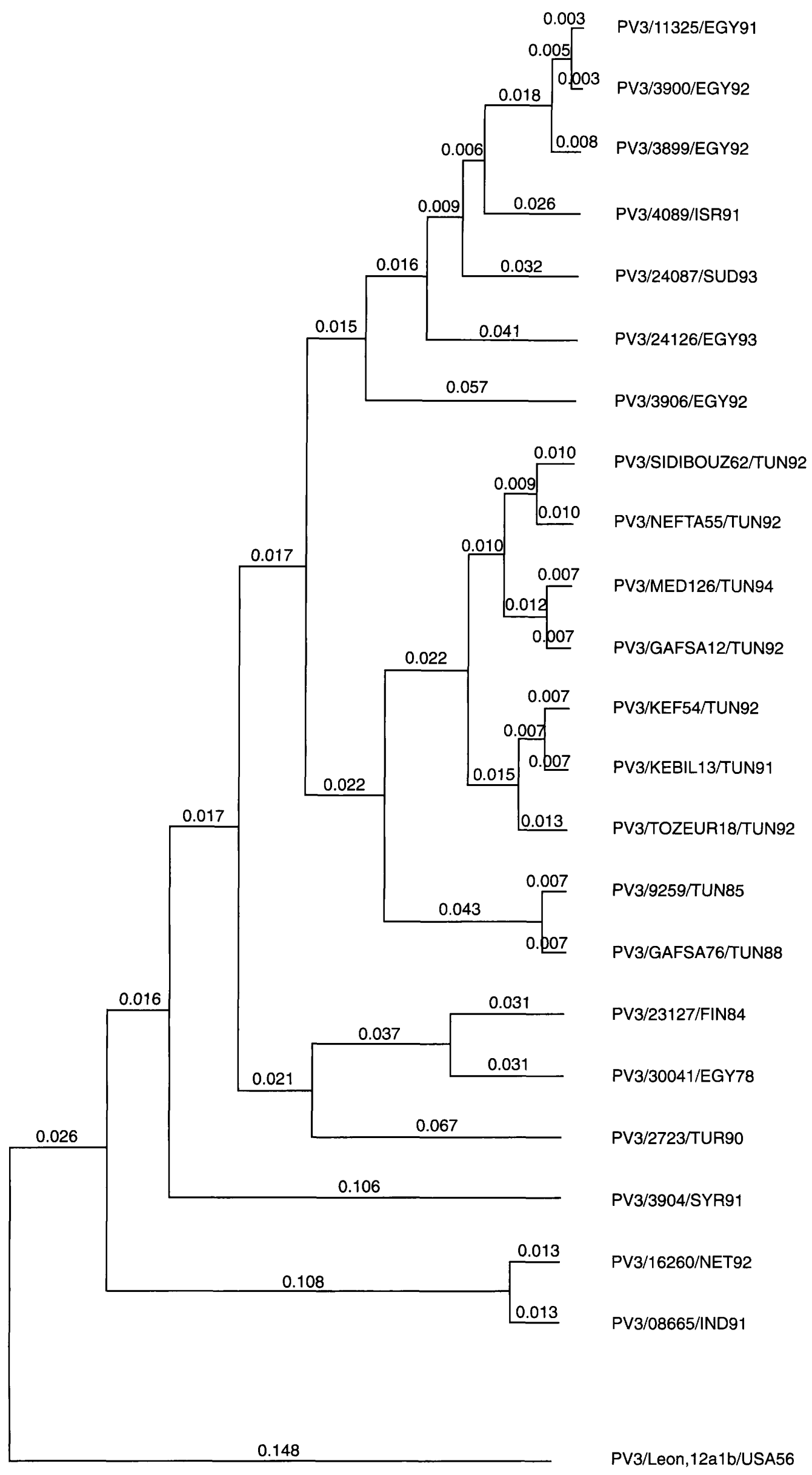




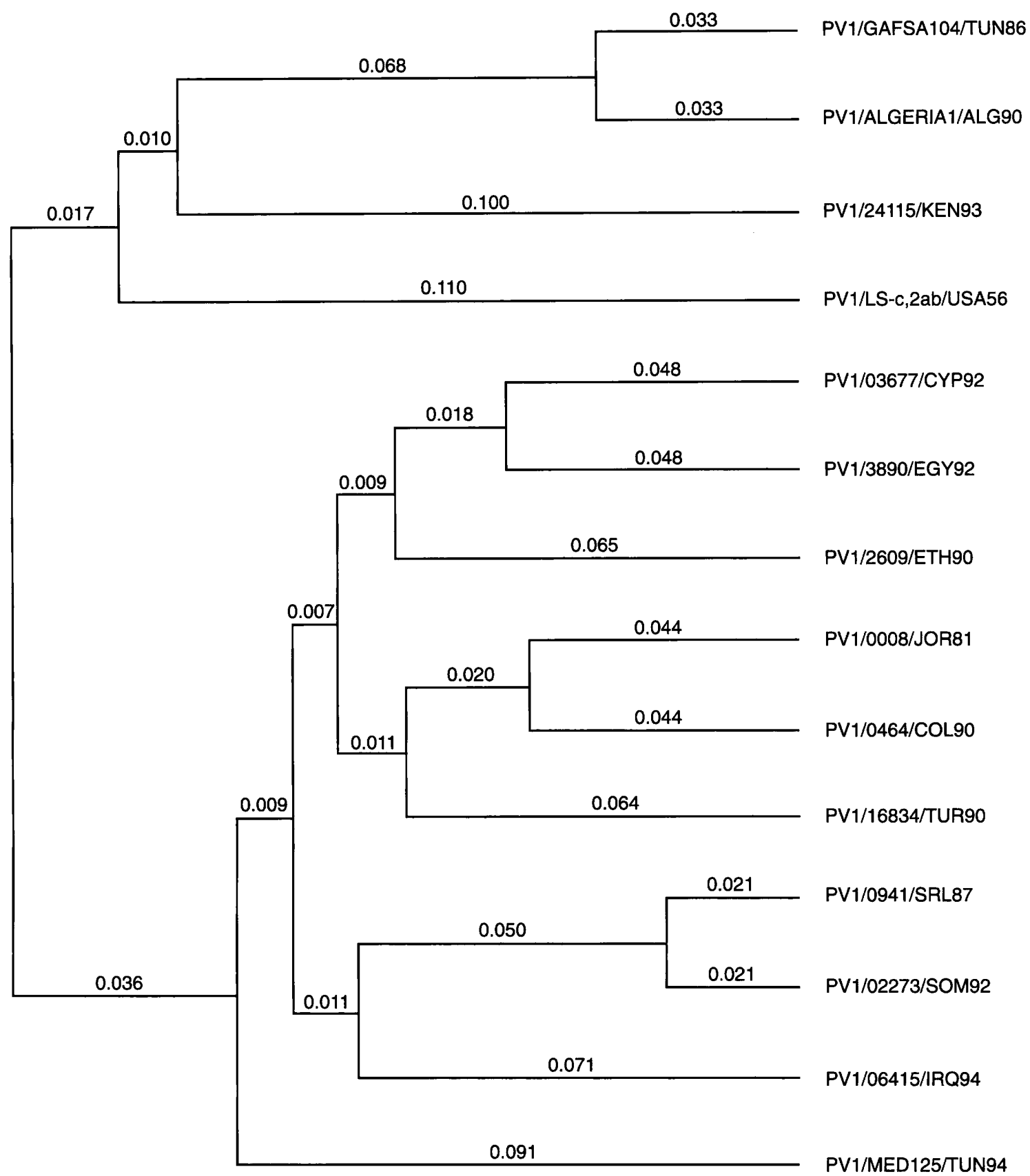

Fig. 3. Sequence relatedness among polio 1 strains. Dendrogram summarising sequence relatedness among polio 1 strains across the nucleotides $3296-3445$ in the VP1/2A region [20]. Strain designation and abbreviations are as defined in the legend to Fig. 2.

In Tunisia, a national programme for virological surveillance of AFP cases was started at the end of 1991. The AFP case detection rate increased gradually and became $>1$ case $/ 100000$ infants $<15$ years of age since 1995. This rate is the minimum required and used by WHO as a performance indicator to monitor the sensitivity of case detection by National Surveillance Programmes [38]. From 1991 to 1996, this laboratory investigated $152 \mathrm{AFP}$ cases and 1762 of their contacts. A total of 2088 stool samples was analysed with 101 individuals proving poliovirus positive. All polioviruses were investigated for their wild or vaccine-related origin by two methods and genotypes were studied by partial genome sequencing of 12 selected representative strains. The last cases of paralytic poliomyelitis in Tunisia occurred between December 1991 and April 1992: six cases caused by wild polio 3 virus were reported and, because $<1 \%$ of infected children show signs of AFP, the number of asymptomatic infections was estimated at between 600 and 6000. This 'outbreak' or 'resurgence' of the disease after $>2$ polio-free years could be simply the result of the improved surveillance system or due to the introduction of a new genotype into the country. In this study, all Tunisian polio 3 strains were found to belong to the same genotype: strains isolated in 1992 and 1994 were most closely related to the Tunisian strains isolated in 1985, which illustrates continuous 
circulation of a Tunisian polio 3 genotype between 1985 and 1994 and suggests that there is apparently no virus importation from other countries of the African and Mediterranean regions. The Tunisian polio 1 strain isolated in 1986 was closely related to an Algerian strain isolated in $1990(6 \%$ difference in nucleotide sequence). Accordingly, the two strains could represent a country/region specific genotype. In contrast, the wild polio 1 isolate in 1994 (PV1/ MED125/TUN94) had $>18 \%$ dissimilarity to that isolated in 1986. No other related sequence could be found among strains that have been circulating in the Mediterranean and African region and, thus, its origin remains unclear. This strain could represent a second Tunisian genotype or a virus imported from another country where the circulating polioviruses are incompletely characterised. Genotypic analysis of circulating polio strains is incomplete in some areas of the world [31]; the Maghrebian region is an example of such an area and this highlights the importance of the present study. However, a more comprehensive view will require examination of isolates from neighbouring countries. Although long range importation of polioviruses does occur $[19,22,31-37,39]$, most transmission takes place between adjacent areas [31] and poliomyelitis control strategies are more effective if undertaken at a regional level.

The other finding of this study was that, during the last decade, all polio type 2 viruses circulating in Tunisia were vaccine-related and most wild-type viruses belonged to the serotype 3 with a single genotype. These results reflect effective control strategies within the country. As vaccine coverage increases in a region, there is a decrease in poliomyelitis cases followed by a decrease in the genetic variability of circulating polioviruses and the most rapid disappearance of serotype $2[25,31,40]$. The continued circulation of wild-type 2 polioviruses is an indication of serious deficiencies in polio vaccine coverage. Wild type 2 poliovirus circulation was sharply reduced, presumably because of the greater immune protection afforded by type 2 infection than by the two other serotypes [41]. The fact that most wild viruses isolated in Tunisia in the last decade belong to serotype 3 and that infection occurred in fully vaccinated children could be due to the incomplete protection of Tunisian OPV vaccinated children against this serotype. Low seroconversion rates to polio 3 in fully vaccinated Tunisian infants have been reported already [42], which is certainly the principal factor contributing to persistent circulation of wild type 3 poliovirus, in spite of a high OPV coverage. Several studies have reported poliomyelitis outbreaks and poliovirus circulation in fully vaccinated populations [43-47]. This illustrates that achieving high routine vaccination coverage rate is insufficient to eradicate the disease. The re-emergence of paralytic poliomyelitis in 1991-1992 in Tunisia, after $>2$ years of no polio paralytic case detection, and the re- isolation of the same indigenous strain in 1994, in spite of a high OPV coverage for many years and intensive OPV vaccination campaigns conducted in 1992 in response to the six polio cases, underlines the extreme difficulties in interrupting the circulation of wild polioviruses in a region. There remains a need for surveillance in countries with intensive OPV vaccination strategies and where the disease has apparently been eradicated. This also highlights the efforts that still are to be undertaken in endemic areas. It is likely that by now the circulation of wild polioviruses in Tunisia has been interrupted, as routine immunisation has been supplemented by annual National Immunization Days (NIDs) since 1995. This strategy has proved highly effective in interrupting wild virus circulation in many regions of the world [48-50]. However, this positive impact can be stated only after several years of no detection of wild viruses in the presence of a highly effective AFP surveillance programme.

We thank the Directory of Primary Health Care in Tunisia, with special thanks to Dr Mohsni Ezzeddine and the National staff of the Ministry of Health at all levels, for their efforts in the field work as part of the case investigations and for providing epidemiological and clinical data.

\section{References}

1. World Health Assembly (41st) Geneva, 2-13 May. Global eradication of polio by the year 2000. Resolutions and decisions. WHO (Resolution WHA 41, 28) 1988; 26.

2. World Health Organization. Performance of Acute Flaccid Paralysis (AFP) surveillance and incidence of poliomyelitis, 1996-1997. Wkly Epidemiol Rec 1997; 72: 208-210.

3. van Wezel AL, Hazendonk AG. Intratypic serodifferentiation of poliomyelitis virus strains by strain-specific antisera. Intervirology 1979; 11: 2-8.

4. Crainic R, Couillin P, Blondel B, Cabau N, Boué A, Horodniceanu F. Natural variation of poliovirus neutralization epitopes. Infect Immun 1983; 41: 1217-1225.

5. Osterhaus ADME, van Wezel AL, Hazendonk TG, UytdeHaag FGCM, van Asten JAAM, van Steenis B. Monoclonal antibodies to polioviruses. Comparison of intratypic strain differentiation of poliovirus type 1 using monoclonal antibodies versus cross-absorbed antisera. Intervirology 1983; 20: $129-136$.

6. Glikmann G, Moynihan M, Petersen I, Vestergaard BF. Intratypic differentiation of poliovirus strains by enzyme-linked immunosorbent assay (ELISA): poliovirus type 1. Dev Biol Stand 1983; 55: 199-208.

7. Ferguson M, Macgrath DI, Minor PD, Schild GC. WHO collaborative study on the use of monoclonal antibodies for the intratypic differentiation of poliovirus strains. Bull World Health Organ 1986; 64: 239-246.

8. Hyypiä T, Auvinen P, Maaronen M. Polymerase chain reaction for human picornaviruses. $J$ Gen Virol 1989; 70: 3261-3268.

9. Chapman NM, Tracy S, Gauntt CJ, Fortmueller U. Molecular detection and identification of enteroviruses using enzymatic amplification and nucleic acid hybridization. J Clin Microbiol 1990; 28: 843-850.

10. Olive DM, Al-Mufti S, Al-Mulla W et al. Detection and differentiation of picornaviruses in clinical samples following genomic amplification. J Gen Virol 1990; 71: 2141-2147.

11. Petitjean J, Quibraic M, Freymuth F et al. Specific detection of enteroviruses in clinical samples by molecular hybridization using poliovirus subgenomic riboprobes. $J$ Clin Microbiol 1990; 28: 307-311.

12. Balanant J, Guillot S, Candrea A, Delpeyroux F, Crainic R. The natural genomic variability of poliovirus analyzed by a 
restriction fragment length polymorphism assay. Virology 1991; 184: $645-654$

13. da Silva EE, Pallansch MA, Holloway BP, Oliveira MJC, Schatzmayr HG, Kew OM. Oligonucleotide probes for the specific detection of the wild poliovirus types 1 and 3 endemic to Brazil. Intervirology 1991; 32: 149-159.

14. Yang CF, De L, Holloway BP, Pallansch MA, Kew OM. Detection and identification of vaccine-related polioviruses by the polymerase chain reaction. Virus Res 1991; 20: 159-179.

15. Kämmerer U, Kunkel B, Korn K. Nested PCR for specific detection and rapid identification of human picornaviruses. $J$ Clin Microbiol 1994; 32: 285-291.

16. Schweiger B, Schreier E, Böthig B, López-Pila JM. Differentiation of vaccine and wild-type polioviruses using polymerase chain reaction and restriction enzyme analysis. Arch Virol 1994; 134: 39-50.

17. Takeda N, Sakae K, Agboatwalla $M$, Isomura $S$, Hondo $R$ Inouye $\mathrm{S}$. Differentiation between wild and vaccine-derived strains of poliovirus by stringent microplate hybridization of PCR products. J Clin Microbiol 1994; 32: 202-204.

18. De L, Nottay B, Yang C-F, Holloway BP, Pallansch MA, Kew O. Identification of vaccine-related polioviruses by hybridization with specific RNA probes. $J$ Clin Microbiol 1995; 33: 562-571.

19. Rico-Hesse R, Pallansch MA, Nottay BK, Kew OM Geographic distribution of wild poliovirus type 1 genotypes. Virology 1987; 160: 311-322.

20. Kew OM, Nottay BK, Rico-Hesse R, Pallansch MA. Molecular epidemiology of wild poliovirus transmission. In: Kurstak E Marusyk RG, Murphy FA, Van Regenmortel MHV (eds) Applied virology research, Vol 2. Virus variability, epidemiology, and control. New York, Plenum Medical Book Co. 1990: 199-221.

21. Kew OM, Pallansch MA, Nottay BK Rico-Hesse RR, De L. Yang C-F. Genotype relationships among wild polioviruses from different regions of the world. In: Brinton MA, Heinz FX (eds) New aspects of positive-strand RNA viruses. Washington, DC, American Society for Microbiology. 1990: 357-365.

22. Pöyry T, Kinnunen L, Kapsenberg J, Kew O, Hovi T. Type 3 poliovirus/Finland/1984 is genetically related to common Mediterranean strains. J Gen Virol 1990; 71: 2535-2541.

23. Kew O, De L, Yang CF, Nottay B, da Silva E, Pallansch M. The role of virlologic surveillance in the global initiative to eradicate poliomyelitis. In: Kustak $\mathrm{E}$ (ed) Control of virus diseases, 2nd edn. New York, Marcel Dekker. 1993: 215-246.

24. Zheng D-P, Zhang L-B, Fang Z-Y et al. Distribution of wild type 1 poliovirus genotypes in China. $J$ Infect Dis 1993; 168: 1361-1367.

25. Mulders MN, Lipskaya GY, van der Avoort HGAM, Koopmans MPG, Kew OM, van Loon AM. Molecular epidemiology of wild poliovirus type 1 in Europe, the Middle East, and the Indian subcontinent. $J$ Infect Dis 1995; 171: 1399-1405.

26. Triki H, Arrouji A, Dellagi K. [Acute anterior poliomyletitis. Situation in Tunisia during 1991-1992.] La poliomyélite Antérieure Aigûe: situation en Tunisie en 1991-1992. Arch Inst Pasteur Tunis 1992; 69: 21-27.

27. Expanded Programme on Immunization. Surveillance for polio - the Tunisia experience. EPI Alert 1993; 8: 7.

28. World Health Organization. Poliomyelitis eradication - Tunisia. Wkly Epidemiol Rec 1994; 46: 344-347.

29. World Health Organization. Manual for the virological investigation of poliomyelitis. Geneva, WHO. 1992 (WHO/ EPI/CDS/POLIO/90.1).

30. van der Avoort HGAM, Hull BP, Hovi $\mathrm{T}$ et al. Comparative study of five methods for intratypic differentiation of polioviruses. J Clin Microbiol 1995; 33: 2562-2566.
31. Kew OM, Mulders MN, Lipskaya GY et al. Molecular epidemiology of polioviruses. Seminars Virology 1995; 6: 401-414.

32. Mulders $\mathrm{MN}$, van Loon AM, van der Avoort HGAM et al. Molecular characterization of wild poliovirus type 3 epidemic in the Netherlands (1992 and 1993). J Clin Microbiol 1995; 33: $3252-3256$

33. Bernal A, García-Saíz A, Liacer A, de Ory F, Tello O, Nájera R. Poliomyelitis in Spain, 1982-1984: virologic and epidemiologic studies. Am J Epidemiol 1987; 126: 69-76.

34. Varughese PV, Carter AO, Acres SE, Furesz J. Eradication of indigenous poliomyelitis in Canada: impact of immunization strategies. Can J Public Health 1989; 80: 363-368.

35. World Health Organization. Expanded programme on immunization. Poliomyelitis outbreak: Bulgaria. Wkly Epidemiol Rec 1992; 67: 336-337.

36. World Health Organization. Expanded programme on immunization. Poliomyelitis outbreak: Malaysia. Wkly Epidemiol Rec 1993; 68: 297-300.

37. Oostvogel PM, van Wijngaarden JK, van der Avoort HGAM et al. Poliomyelitis outbreak in an unvaccinated community in the Netherlands, 1992-93. Lancet 1994; 344: 665-670.

38. Hull HF, Birmingham ME, Melgaard B, Lee JW. Progress toward global polio eradication. J Infect Dis 1997; 175 Suppl 1: S4-S9.

39. Pan American Health Organization. Polio incidence rises in Brazil northeast. EPI Newsl 1986; 8: 4-5.

40. World Health Organization Collaborative Study Group on Oral Poliovirus Vaccine. Factors affecting the immunogenicity of oral poliovirus vaccine: a prospective evaluation in Brazil and the Gambia. J Infect Dis $1995 ; 171$ 1097-1106.

41. Hull BP, Dowdle WR. Poliovirus surveillance: building the global polio laboratory network. J Infect Dis 1997; 175 Suppl 1: S113-S116.

42. Triki H, Ould Mohamed Abdallah MV, Ben Aissa R et al. Influence of host related factors on the antibody response to trivalent oral polio vaccine in Tunisian infants. Vaccine 1997; 15: $1123-1129$.

43. Kim-Farley RJ, Rutherford G, Lichfield $P$ et al. Outbreak of paralytic poliomyelitis, Taiwan. Lancet 1984; 2: 1322-1324.

44. Sutter RW, Patriarca PA, Brogan S et al. Outbreak of paralytic poliomyelitis in Oman: evidence for widespread transmission among fully vaccinated children. Lancet 1991; 338: $715-720$.

45. Chiba Y, Xu A, Li L et al. Outbreaks of paralytic poliomyelitis and polio surveillance in Shandong province of China. Jpn $J$ Med Sci Biol 1992; 45: 255-266.

46. Deming MS, Jaiteh KO, Otten MW et al. Epidemic poliomyelitis in the Gambia following the control of poliomyelitis as an endemic disease. II. Clinical efficacy of trivalent oral polio vaccine. Am J Epidemiol 1992; 135: 393-408.

47. Otten MW, Deming MS, Jaiteh KO et al. Epidemic poliomyelitis in the Gambia following the control of poliomyelitis as an endemic disease. 1. Descriptive findings. $A m J$ Epidemiol 1992; 135: 381-392.

48. Birmingham ME, Aylward RB, Cochi SL, Hull HF. National immunization days: state of the art. J Infect Dis 1997; 175 Suppl 1: S183-S188.

49. Olivé J-M, Risi JB, de Quadros CA. National immunization days: experience in Latin America. $J$ Infect Dis 1997; 175 Suppl 1: S189-S193.

50. Bilous J, Maher C, Tangermann RH et al. The experience of countries in the Western Pacific Region in conducting National immunization days for poliomyelitis eradication. $J$ Infect Dis 1997; 175 Suppl 1: S194-S197. 